\title{
La relevancia idiosincrásica de la muerte y los cementerios. Turismo en el cementerio ochocentista de Conchada (Coimbra, Portugal): públicos, motivaciones, interpretaciones y reflexiones
}

Sara Filipa dos Reis Madeira | Faculdade de Letras da Universidade de Coimbra (FLUC)

URL de la contribución <www.iaph.es/revistaph/index.php/revistaph/article/view/5075>

Con la publicación en 2000 de la monografía Dark Tourism: The Attraction of Death and Disaster, Lennon y Foley definieron el concepto como la inclusión de eventos que involucran muerte, desastres y atrocidad en el contexto de la memoria viva (Light 2017), vinculando el desarrollo de sitios de Dark Tourism a una inherente curiosidad humana sobre la mortalidad y los aspectos más oscuros de la humanidad (Lennon y Foley 2000, citados por Fonseca, Seabra y Silva 2016). La muerte puede revelar tanto valores como procesos sociales y culturales, convirtiéndose en un catalizador que, al entrar en contacto con cualquier orden cultural, precipita las creencias y preocupaciones centrales de un pueblo (Kearl 2009, citado por Stone 2012). En cambio, en un enfoque individual, la expresión latina memento mori no se restringe a las representaciones de la muerte en el contexto del arte, la literatura, el folclore o la religión, sino que se extiende al consumo de Significant Other Death (otra muerte significativa) a través de experiencias turísticas con un componente oscuro, permitiendo que el Yo construya y reflexiones sobre el significado de la muerte (Stone 2012). Desde esta perspectiva, destaca una de las diversas tipologías del Dark Tourism, el turismo de cementerio, entendido como el movimiento de personas en espacios sepulcrales con el propósito de observar sepulturas, tumbas o mausoleos (Fonseca, Seabra y Silva 2016).

En el contexto funerario, los cementerios surgen como una respuesta material a la necesidad existencialista del concepto de eternidad, legitimándose, en particular, el cementerio del siglo XIX como espacio de reproducción simbólica del universo sociocultural y de las expectati- vas metafísicas, fundamental para una simbiosis entre los muertos y la conciencia de la de memoria, patentes en la representación hecha del difunto a través de los elementos artísticos del cementerio (Pegas 2013). Así, las tumbas ochocentistas manifiestan dos realidades simbióticas: "lo invisible" (cuerpo enterrado) y lo "visible" que, en opinión de Bernardin de Saint-Pierre, en la Revista dos Monumentos Sepulchrais (1868), considera la tumba como un monumento entre las fronteras de dos mundos (Pegas 2013). Sin embargo, con el declive del romanticismo, los cementerios del siglo XIX, considerados como espacios para pasear y admirar la monumentalidad del arte sepulcral, acusan un descenso en la frecuencia de ser escogidos como lugares preferidos para las visitas, mientras que en los años sesenta y setenta del siglo XX resurge la consideración del cementerio, valorando la concepción del mismo como herencia cultural y patrimonial (Queiroz 2007).

Partiendo de la premisa de valorización de los cementerios del siglo XIX, entre noviembre de 2019 y marzo de 2020 desarrollé una ruta de turismo de cementerio en el de Conchada, en Coimbra (Portugal) complementada con visitas guiadas, en colaboración con entidades públicas y privadas de la ciudad, en el marco de la Maestría en Turismo, Territorio y Patrimonio (Facultad de Artes de la Universidad de Coimbra-FLUC). Considerando que el inmueble, inaugurado en 1860, se encuentra actualmente en proceso de clasificación por la Dirección General de Patrimonio Cultural (DGPC), con propuestas del Ayuntamiento de Coimbra para la eventual clasificación del cementerio de Conchada como Conjunto de Interés Público (CIP) y destacando el reconocimiento, 
en 2013 , de la Universidad de Coimbra-Alta y Sofía por parte de la Organización de las Naciones Unidas para la Educación, la Ciencia y la Cultura (UNESCO) como Patrimonio de la Humanidad, entendí que era pertinente desarrollar actividades turísticas que diversificaran la oferta turística de la ciudad al tiempo que legitimasen la relevancia cultural e histórica del espacio sepulcral mencionado, considerando la presencia de tumbas y mausoleos donde descansan o son homenajeadas personalidades cuyo impacto social, cultural, literario o artístico influyó en la memoria de Coimbra. Asimismo, existen monumentos funerarios caracterizados por movimientos artísticos historicistas, desarrollados durante la segunda mitad del siglo XIX y principios del siglo XX, en hierro y piedra, diseñados por artesanos de Coimbra.

Como parte de una ruta que incluyó 23 puntos de interés, se realizaron 16 visitas guiadas, pro bono, con un numerus clausus de 25 visitantes, con un total de 82 participantes, entre público en general y estudiantes de la Maestría en Turismo, Territorio y Patrimonio (FLUC). Al final de cada visita se solicitaba la cumplimentación de una serie de cuestionarios elaborados con el objetivo de interpretar las motivaciones de los visitantes en relación a la demanda turística de los espacios de cementerio. La metodología subrayada permitió destacar algunas conclusiones significativas, de las cuales destaco: (1) Las motivaciones de los visitantes recaían mayoritariamente en características culturales, históricas, artísticas y de curiosidad; (2) Un número considerable de participantes reconoció haber visitado previamente tanto cementerios como espacios asociados a la muerte en un contexto turístico; (3) La mayoría de los visitantes residían en el municipio de Coimbra, tenían entre 20 y 86 años, y gran parte eran graduados universitarios; (4) Una parte menos significativa de los estudiantes de la Maestría indicó desinterés por el tema del cementerio, defendiendo lo inadecuado del uso de los espacios funerarios en el ámbito de las rutas turísticas.

Los datos disponibles permitieron interpretar e inferir conclusiones importantes. La existencia de un numerus clausus permite prevenir la masificación de la demanda

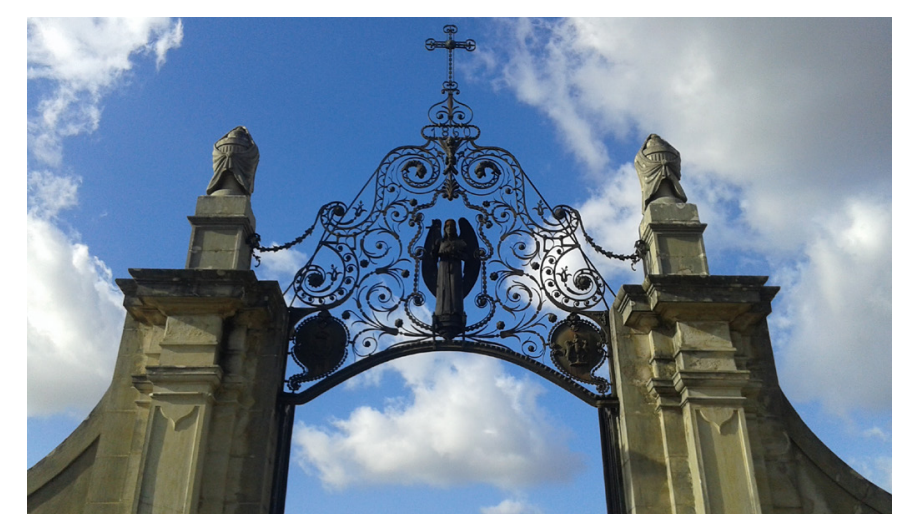

Puerta Principal del Cementerio en la Conchada, Coimbra, Portugal | foto Sara Filipa dos Reis Madeira

de cementerios en un contexto turístico, abogando por la integridad, autenticidad y dignificación de estos sitios, asegurando su patrimonio y sostenibilidad idiosincrásica desde una perspectiva ética. Asimismo, determinando previamente número de visitantes que pueden participar en cada recorrido, se posibilita una experiencia pedagógica específica. En mi caso, la determinación de un numerus clausus me permitió interactuar, de manera individual, con los visitantes, como investigadora y guía turística, valorando sus aportaciones durante el camino, y esos diálogos contribuyeron a la inclusión de información y puntos de interés en visitas posteriores, reconociendo a los participantes como agentes informados, dinámicos y proactivos. Además, constaté que, en quienes se unían las visitas guiadas, había un predominio de generaciones nacidas entre los años 40 y 90 del siglo XX, lo que respalda la abundancia de temas compartidos durante el recorrido en torno a la historia local y regional de Coimbra, demostrando que la heterogeneidad etaria de los visitantes no discrimina ni genera barreras generacionales en el contexto subjetivo de sus motivaciones intrínsecas y de las narrativas patrimoniales de los cementerios.

Concluyo este texto con un comentario sobre el punto 4 al que me refería anteriormente: "Una parte menos significativa de los estudiantes de la Maestría indicó desinterés por el tema del cementerio, defendiendo lo inadecuado del uso de los espacios de cementerio en 
a debate Interpretación y gestión del patrimonio en los espacios del turismo oscuro

| coordinan Óscar Navajas Corral y Maribel Rodríguez Achútegui

el ámbito de las rutas turísticas". A mi entender, hay una parte importante de la sociedad contemporánea que ya no se ve a sí misma en una matriz cristiana, percibiendo las actividades turísticas en los cementerios como irrazonables o extrañas. En una sociedad caracterizada por las plataformas digitales, potenciando los selfies y el narcisismo, los cementerios pueden asociarse al miedo a la muerte y al deterioro físico, a la reflexión sobre la condición humana y la valoración del patrimonio cultural, artístico, histórico o social presente en estas necrópolis ochocentistas, no solo estigmatizadas sino en peligro de extinción. Es fundamental desmitificar el aura de la ritualización cristiana de los sitios funerarios para poder percibir la muerte, en esos escenarios patrimoniales que son los cementerios, como un proceso holístico en el contexto multifacético del legado humano. Los restos materiales o inmateriales de los cementerios decimonónicos se volverían perecederos, obsoletos o extintos si se ocultara su vertiente cultural en favor de un discurso hegemónico e idealizado motivado por la glorificación de la ilusión que brinda el escapismo digital de lo efímero. La conciencia política, turística, cívica y comunitaria en esta materia es fundamental. Quedan la reflexión, el debate y el desafío.

\section{BIBLIOGRAFÍA}

- Fonseca, A., Seabra, C. y Silva, C. (2016) Dark Tourism: Concepts, Typologies and Sites. Journal of Tourism Research \& Hospitality, 2016, S2. Disponible en: https://repositorio.ipv.pt/ bitstream/10400.19/3370/1/dark-tourism-concepts-typologiesand-sites-Egqw.pdf [Consulta: 27/11/2021]

- Light, D. (2017) Progress in Dark Tourism and Thanatourism Research: An Uneasy Relationship with Heritage Tourism. Tourism Management, vol. 61, pp. 275-301. Disponible en: http:// eprints. bournemouth.ac.uk/29128/1/2017\%20Progress\%20 in\%20dark\%20tourism\%20and\%20thanatourism\%20research. pdf [Consulta: 27/11/2021]

- Pegas, A. (2013) O visível que não se vê e o património cemiterial: proposta de criação de uma Rota Turística dos Cemitérios do Porto. Tesis de Maestría. Faculdade de Letras da Universidade do Porto (Portugal). Disponible en: https://repositorio-aberto.up.pt/bitstream/10216/72271/2/ tesemestanapegasvisivel000223430.pdf [Consulta: 28/11/2021]
- Queiroz, F. (2007) Os Cemitérios Históricos e o seu Potencial Turístico em Portugal. Anuário 21 Gramas. Disponible en: http:// www.franciscoqueiroz.com/Cemiterios_historicos_Potencial Turistico_Portugal_\%20versao_21_gramas.pdf [Consulta: 28/11/2021]

- Stone, P. (2012) Dark Tourism and Significant Other Death. Towards a Model of Mortality Mediation. Annals of Tourism Research, vol. 39, n. ${ }^{\circ} 3$, pp. 1565-1587. Disponible en: https://www. sciencedirect.com/science/article/abs/pii/S0160738312000564 [Consulta: 28/11/2021] 